2015

\title{
Can We Use Polya's Method to Improve Students' Performance in the Statistics Classes?
}

Indika Wickramasinghe

Eastern New Mexico University - Main Campus, wickramasingheindika@gmail.com James Valles

Prairie View A\&M University

Follow this and additional works at: https://digitalcommons.usf.edu/numeracy

Part of the Science and Mathematics Education Commons

\section{Recommended Citation}

Wickramasinghe, Indika, and James Valles. "Can We Use Polya's Method to Improve Students' Performance in the Statistics Classes?." Numeracy 8, Iss. 1 (2015): Article 12. DOI: http://dx.doi.org/ 10.5038/1936-4660.8.1.12 


\title{
Can We Use Polya's Method to Improve Students' Performance in the Statistics Classes?
}

\author{
Abstract \\ In this study, Polya's problem-solving method is introduced in a statistics class in an effort to enhance \\ students' performance. Teaching the method was applied to one of the two introductory-level statistics \\ classes taught by the same instructor, and a comparison was made between the performances in the two \\ classes. The results indicate there was a significant improvement of the students' performance in the \\ class in which Polya's method was introduced.

\section{Keywords} \\ Teaching Statistics; Polya's Problem-Solving Method; Student's Performance

\section{Creative Commons License} \\ (c) (1) (2) \\ This work is licensed under a Creative Commons Attribution-Noncommercial 4.0 License

\section{Cover Page Footnote} \\ Indika Wickramasinghe is an assistant professor of statistics at Eastern New Mexico University (ENMU), \\ where he teaches in the Department of Mathematical Sciences. He taught in Texas Tech University, where \\ he obtained in PhD before joining ENMU. He is currently researching saddlepoint approximation in \\ statistics, sports data analysis, and mathematical/statistical education. \\ James Valles, Jr. is an assistant professor of mathematics at Prairie View A\&M University in Prairie View, \\ Texas. He was awarded a Ph.D. from Texas Tech University, specializing in complex analysis. He began \\ his post-secondary teaching carrier in 1998 as a Teaching Assistant at the University of New Mexico. \\ Currently he is teaching math content courses for pre-service teachers. Research interests include pre- \\ service teacher mathematical self-efficacy, issues regarding minorities in education, and logarithmic \\ potential theory.
}




\section{Introduction}

As teachers of statistics and quantitative reasoning, our primary goal is to provide students the critical thinking skills necessary to allow flexible thinking with open minds when analyzing practical problems. Student interest in our subjects plays a major role in achieving this stated goal. Therefore, as teachers we all attempt to make the subject interesting to our students. Emphasizing the basic pedagogical elements of undergraduate education is one way of achieving this. In their general education programs, many colleges have included pedagogical elements such as active learning, making connections between disciplines, and drawing upon students' experiences with an idea of accomplishing the above goal (Rumsey 1998). The literature suggests that students learning statistics encounter a variety of difficulties with the subject. Blanco and Ginovart (2009), for example, argued that teaching probability is a challenge because of conceptual difficulties in the topic.

Focusing on statistics, Zieffler et al. (2008) stated that even high-performing students find it difficult to explain abstract concepts such as the central limit theorem. Sotos et al. (2007) considered that one of the main reasons students find inferential statistics difficult is the presence of misconceptions. Richardson and Haller (2002) discussed a hands-on activity to teach statistical concepts including generating, collecting, displaying and analyzing data. Post et al. (2012) studied how to teach students the concepts about hypothesis in order to improve their skills in both application and the interpretation of the concepts. In addition to the pedagogical issues, a student's prior knowledge of statistics, culture of the classroom, and methods of evaluating students are some other important aspects that we need to consider in this process.

There has been a variety of attempts made to improve students' statistical understanding. The literature suggests that most attempts are directed towards the use of the technology. Comparatively little attention has been given to nontechnological methods that can improve students' understanding. One of the main benefits of non-technological methods is that they can be applied in institutions with limited resources including both expenditure for buying new technologies and trained human resources. Although there is a huge debate about technological vs. non-technological methods, our aim is not to argue on this. As Garfield (1995) pointed out, even in college-level courses, students show issues with learning, remembering, and utilizing statistics. Statistical problem solving is integral in the process of learning statistics.

In problem solving, we instructors have seen the common behavior of the statistics students jumping directly to follow an arbitrary plan without even reading and understanding the question properly. These students blindly tend to 
pick a formula and plug in values and, at the end, stop abruptly. In the long run, these kinds of unsuccessful behaviors motivate the students not to try a problem again. At times, the students forget to check the validity of the answer they get through their ad hoc method. This is very evident when grading questions in probability, as some students provide answers that are greater than one, which, of course, is an unacceptable answer. This is where a structured problem-solving method such as the Polya's becomes helpful, as it guides students to find the solution to the problem through an easy-to-follow sequence of four steps, namely, understanding the problem, devising a plan, carrying out a plan, and looking back.

In the study reported here, we attempted to improve students' problemsolving skills in an introductory statistics class by using Polya's Problem Solving Method.

\section{Background}

Students' engagement with the problem-solving process not only trains them to solve specific problems, but it also helps them to understand the related variables and formulate the problem (Cobb et al. 1991). Schifter and Fosnot (1993) see the problem-solving approach as a vehicle to improve students' confidence in thinking mathematically. Gal and Garfield (1997) describe an attempt to devise a framework for assessing a student's problem-solving behavior in a small-group setting. In another study, Marriott (2009) reports the findings of a survey about the development of a novel teaching material based on a statistical problemsolving approach.

While there is plentiful evidence of the use of Polya's methodology in the classroom for other disciplines, such as mathematics, there is little in the literature on bringing Polya's problem-solving methods to statistics classes. Xin et al. (2011) compared two problem-solving models on students' success in multiplication and division word problems of elementary students. According to the results they obtained, the authors pointed out that the conceptual-model-based problem-solving method improved students' understanding better than that of the problem-solving method based on a general heuristic instructional approach.

Selvaratnam (2011) compared five problem-solving strategies to test the competence of the students in a BSc course of Chemistry. That author found that none of the strategies improved the students' competence in cognitive strategies competency and suggested that one of the main reasons for this was that these strategies did not transfer to different type of problems. In another study, Selvaratnam and Mavuso (2010) studied the competencies of science students using carefully designed questions to test whether students use the selected strategies of clarifying problems, identifying rules associated with the solution, 
focusing on the goal, handling the equations, and achieving the solution in a stepby-step manner.

Lin (2011) investigated the impact of a web-based collaborative-learning methodology on the statistical problem-solving ability of students. In a study of problem-solving strategy scales for teachers and researchers to understand how students solve problems, Gok (2011) developed a scale composed of the following three steps: Item Formulation, Content Validation, and Reliability Calculation. Using students in engineering drawing, Yasin et al. (2012) studied the impact of teaching problem-solving strategies on student achievement, students' knowledge of problem solving, and their problem-solving skills. According to the results of the research, those authors stated that teaching problem-solving techniques successfully increased students' educational achievements. Alter (2012) showed how to incorporate multistep problem-solving methodology to teach strategies for solving mathematics word problems to students with emotional and behavioral disorders. Yunus and Ali (2008) reported an investigation where they determined, through a survey, the students' level of motivation, the level of metacognition in problem solving in mathematics, and the relationship between the level of motivation and overall academic achievement.

Bayazit (2013) analyzed results obtained about students’ problem-solving approach, finding that one of the main mistakes students make is to skip the crucial last step of Polya's (1973) problem-solving method, looking back at the solution. Yuan (2013) argues that Polya's method has influenced educators at all levels and that it helps educators to guide students effectively.

\section{Methodology}

Two sections of an introductory statistics course were taught by the first author in fall 2013, at a regional university in New Mexico. In the course, students were taught the concepts of descriptive statistics, probability, distributions of discrete and continuous random variables, sampling distributions, confidence intervals, and hypothesis testing. For both of these classes, five quizzes and three in-class exams were administered in addition to homework assignments. The instructions were delivered in a face-to-face mode for both classes. The only notable difference was the implementation of Polya's problem-solving methodology in Class 2. This problem-solving methodology was introduced and used in Class 2 after the first in-class exam was over. All the exam grades and quiz grades were recorded in both classes. For the preparation of quizzes, two textbooks, McClave and Sincich (2012) and Devore (2009), were selected. Five quizzes were given for each class during the semester. Quizzes were based on discrete and continuous random variables, sampling distributions, confidence intervals, and hypothesis testing respectively. 
Students were educated about the Polya problem-solving method before it was implemented. They were told that George Polya (1887-1985) can be considered to be one of the popular mathematics educators of the 20th century and that he believed that the problem-solving skills are not an inborn talent but, rather, they need to be learned and practiced. Then, his four steps of problem solving were introduced to the students as follows

Step 1. Understanding the problem

Students were instructed to carefully read the problem, to paraphrase the problem in their own words, to emphasize what they understood, and to determine what the problem wants them to solve (i.e., determine the unknown ).

Step 2. Devising a plan

Students were introduced to some strategies, such as observing the pattern of the problem, recalling similar examples that they came across, making use of diagrams, and writing equations.

Step 3. Carrying out the plan

Students were instructed to implement the strategy they devised in the previous step by performing necessary actions or computations. Most importantly, they were informed to check each calculation in step while proceeding.

Step 4. Looking back

In the final step, students were taught to check the validity of the final solution they found. Most importantly, they were asked to interpret the result they found and to determine whether the solution makes sense and is reasonable in the context of the problem.

The explanation of Polya's problem-solving method was accompanied by examples.

The following is one of the quiz word problems given to both classes. Though the instructor gave the same problem for both classes, students in the class where they were trained with Polya's method answered the quiz according to the Polya's approach.

Example: By mistake, a manufacturer of DVD recording systems included 20 defective systems in a shipment of 100 going out to a small retailer. The retailer has decided to accept the shipment of DVD recorders only if none are found to be defective. Upon receipt of the shipment, the retailer examines only 20 of the systems. What is the probability that there will be 5 or less defectives? 
Polya Step 1: Students read the question and list the given information, using any familiar notation to represent the information.

$\begin{array}{lll}\text { Known: } & \text { Number of defective DVD recorders } & =20 \\ & \text { Total number of DVD recorders } & =100 \\ & \text { Number of DVD recorders the retailer examines } & =20\end{array}$

Unknown: $\quad P$ (at most 5 defectives in the collection of 20)

Polya Step 2: Students see that a particular DVD recorder could be defective or non-defective. That means there are two possibilities with each DVD recorder. The retailer will check 20 DVD recorders. Students eventually recognize that the word problem follows the binomial conditions, and they can apply the binomial distribution.

Polya Step 3: After understanding that the problem calls for the binomial distribution, students need to define the random variable and then determine the two parameters in the distribution. As the question asks about the probability of defective items, the students can define the random variable $X$ as the number of defective DVD recorders out of 20 . As the total number of DVD recorders that the retailer checks is 20 , they have $n=20$. Finally, students need to understand how to find the probability of success, $p$. They go through the information given and recognize that they did not use the other given information. Using the information of total 100 DVD recorders and the 20 defectives, they calculate $p=\frac{20}{100}=0.2$. They need to find $P(X \leq 5)$, which can be calculated using a binomial distribution table as they know both $n$ and $p$. From the binomial distribution table, they find that $P(X \leq 5)=0.804$.

Polya Step 4: At this point, the students need to understand whether this answer makes sense. Since the question is asking about a probability, they know that the answer must be between 0 and 1 . By observing the binomial formula for this problem with $p=0.2$ and $n=20$,

$$
P(X=x)=\frac{n !}{x !(n-x) !} p^{x}(1-p)^{n-x} ; x=0,1, \ldots, 5
$$

students know that the final answer is given by $P(X \leq 5)=P(x=0)+$ $P(x=1)+\cdots+P(x=5)$. Therefore, students can recognize the answer they get should be close to 1 . Also the students know that the answer they calculate represents a probability, therefore it should be a value between 0 and 1. 


\section{Results}

Students' performances on each of the five quizzes in each class are in Tables 1 and 2. Each quiz except quiz 3 had parts A to D. The subparts (A to D) asked students to answer questions such as identifying random variables, interpreting results, calculating test statistics, calculating confidence intervals, and writing null and alternative hypotheses. Tables 1 and 2 show the number of students who took each quiz, the three or four parts of each quiz (A-D), the mean (M) points for each part, and the standard deviation (SD) for each part. According to Tables 1 and 2, it is clear that the average performance of students for the quizzes is higher in Class 2 than in Class 1 . Although the performance of Class 2 is slightly better than Class 1 , the difference is not statistically significant.

Table 1

Performance of Class 1 for the quizzes

\begin{tabular}{|c|c|c|c|c|c|c|c|c|c|c|c|}
\hline \multirow{3}{*}{ Quiz } & \multirow{3}{*}{$\mathbf{N}$} & \multicolumn{10}{|c|}{ Sections of each quiz } \\
\hline & & \multicolumn{2}{|c|}{$\mathbf{A}$} & \multicolumn{2}{|c|}{ B } & \multicolumn{2}{|c|}{ C } & \multicolumn{2}{|c|}{ D } & \multicolumn{2}{|c|}{ Total } \\
\hline & & $\mathbf{M}$ & SD & $\mathbf{M}$ & SD & $\mathbf{M}$ & SD & $\mathbf{M}$ & SD & M & SD \\
\hline 1 & 17 & 1.35 & 3.14 & 3.35 & 3.33 & 3.06 & 4.64 & 3.82 & 4.23 & 11.59 & 11.89 \\
\hline 2 & 13 & 8.08 & 3.84 & 7.70 & 1.79 & 7.31 & 2.72 & 2.62 & 3.57 & 25.69 & 8.08 \\
\hline 3 & 13 & 5.31 & 3.61 & 5.23 & 3.98 & 2.69 & 4.39 & - & - & 13.23 & 9.60 \\
\hline 4 & 12 & 7.42 & 2.50 & 9.08 & 1.88 & 7.50 & 2.84 & 8.50 & 2.94 & 32.50 & 8.87 \\
\hline 5 & 15 & 0.5 & 1.73 & 3.75 & 4.20 & 2.92 & 4.38 & 0.33 & 1.15 & 7.50 & 8.58 \\
\hline
\end{tabular}

Table 2

Performance of Class 2 for the quizzes

\begin{tabular}{ccccccccccccc}
\hline & & \multicolumn{10}{c}{ Sections of each quiz } \\
\cline { 3 - 7 } & N & \multicolumn{1}{c}{ A } & \multicolumn{1}{c}{ B } & \multicolumn{3}{c}{ C } & \multicolumn{2}{c}{ D } & \multicolumn{2}{c}{ Total } \\
\cline { 3 - 13 } & & M & SD & M & SD & M & SD & M & SD & M & SD \\
\hline 1 & 20 & 6.50 & 4.38 & 6.75 & 3.95 & 8.25 & 3.73 & 2.90 & 3.87 & 24.40 & 10.03 \\
2 & 15 & 9.58 & 1.44 & 8.92 & 1.56 & 9.08 & 0.99 & 3.75 & 3.60 & 31.33 & 5.14 \\
3 & 14 & 4.93 & 4.47 & 7.43 & 4.16 & 4.57 & 4.85 & - & - & 13.79 & 9.52 \\
4 & 14 & 7.67 & 2.25 & 8.33 & 4.08 & 10.00 & 0.00 & 9.17 & 2.04 & 35.17 & 7.65 \\
5 & 18 & 3.83 & 3.06 & 5.50 & 4.64 & 3.50 & 4.28 & 1.83 & 2.86 & 14.67 & 10.52 \\
\hline
\end{tabular}

Table 3 shows the performances of students in each class for each exam (three exams and the final). For each exam, the number of students who answered $(\mathrm{N})$, the average number of points (M), and the standard deviation (SD) are displayed. As explained earlier, Polya's method was introduced after the first exam was administered. According to the first exam grades, Class 1 performed 
better than Class 2. Because of the overall lower grades on exam 1, Polya's method was introduced to Class 2. Although the average performances of Class 2 never exceeded that of Class 1, we can note that the gap of the average performances decreased on later exams (Fig. 1).

Table 3

Exam performance

\begin{tabular}{ccccc}
\hline Exam & Class No & N & M & SD \\
\hline 1 & 1 & 21 & 84.71 & 11.32 \\
1 & 2 & 27 & 74.19 & 13.84 \\
2 & 1 & 17 & 63.95 & 15.28 \\
2 & 2 & 19 & 57.94 & 23.58 \\
3 & 1 & 15 & 73.53 & 13.74 \\
3 & 2 & 21 & 69.81 & 13.74 \\
Final & 1 & 20 & 74.80 & 19.00 \\
Final & 2 & 22 & 72.55 & 20.76 \\
\hline
\end{tabular}

When studying the effect of Polya's problem-solving methodology on the students' performances, Figure 1 provides more information. As Table 4 indicates, average performances for the first exam in the two classes are statistically different $(p=0.006)$. After the introduction of Polya's method, the average differences of the two classes decreased. As the results of the statistical procedure indicated, the average differences in the performance of each class are not statistically different with the progression of exams.

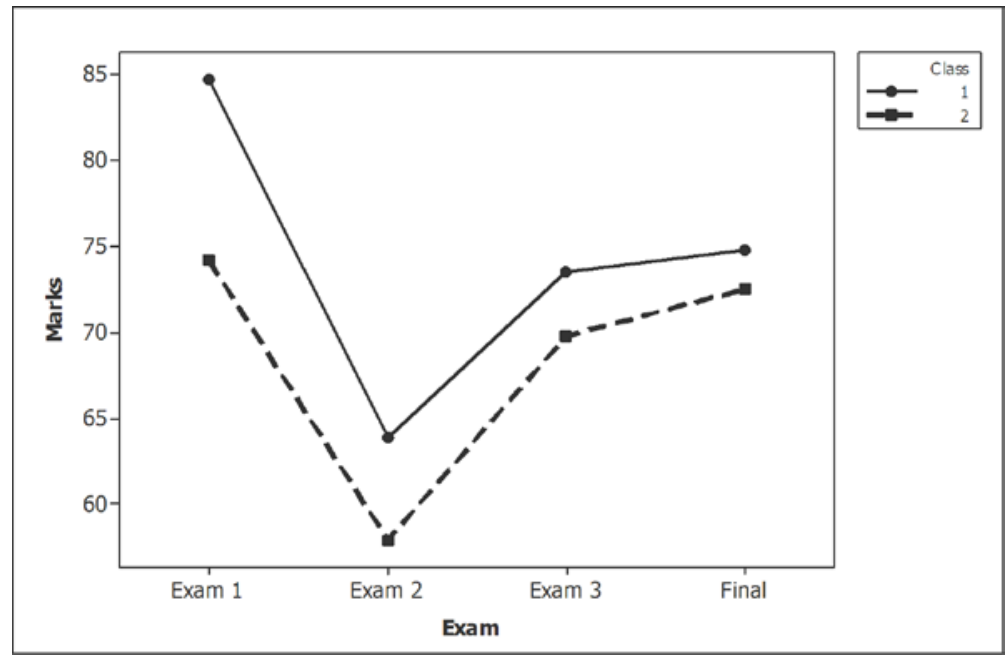

Figure 1. Students' performances for each exam in each class 
Table 4

Mean comparison of two classes

\begin{tabular}{ccc}
\hline Exam & Mean Differences of the performance in two classes & P-value \\
\hline Exam 1 & 10.52 & 0.006 \\
Exam 2 & 6.01 & 0.379 \\
Exam 3 & 3.72 & 0.441 \\
Final & 2.25 & 0.715 \\
\hline
\end{tabular}

\section{Discussion and Conclusion}

Statistical problem solving, which impacts on students' performance in the statistics class, has been a major concern in all levels of statistics education. In this study, an attempt was made to improve student performance through the enhancement of their skills of problem solving. Polya's problem-solving method was utilized as the vehicle for achieving this goal.

According to the results (Tables 1 and 2), Class 2 students' performance on the quizzes was slightly higher than that of Class 1 , although the difference was not statistically significant. Students in Class 2 evidently benefitted from the introduction of Polya's method, as they were more comfortable completing the quizzes. Students in Class 1 left some quiz parts unanswered, whereas students in Class 2 listed information derived by using Polya's method, and it helped them to initiate answering the quiz. Another discernable difference between the two classes was illustrated when the students were asked to calculate conditional probabilities. Some students computed a value greater than 1, but most students in Class 2 tried to check the solution, based on the last step of Polya's method. Even with questions on hypothesis testing, students in Class 1 had more issues with distinguishing and identifying the population parameter and writing the correct null and the alternative hypotheses than students in Class 2.

The difference in performance on exams (Table 3 and Fig. 1) was of the opposite sign as the quizzes. In Exam 1, students in Class 1 performed better than Class 2, and the difference was statistically significant $(p=0.006)$. After the introduction of Polya's method, this difference of performances decreased with the progression of exams. By the final exam, the gap was at its lowest level. Although the performance of Class 2 did not grow enough to exceed the performance of Class 1 due to the large initial difference, the decrease in the performance gap argues that the introduction of Polya's method helped to improve the performance of Class 2. 
Although Polya's problem-solving method is focused on improving mathematical problem-solving ability (Polya 1973), the outcome of this study suggests that in statistics classes, too, there is room for the applicability of this problem-solving method. It can be a good tool to improve students' poor performance in statistics classes.

\section{Recommendations}

Although all of the steps in Polya's problem-solving method are important, the authors found that paying particular attention to the first step is vital to the success students have in utilizing the other three steps of the problem-solving method. This was obvious when examining the point distribution for quiz \#1, which was on random variables and distributions. Parts $\mathrm{A}, \mathrm{B}$, and $\mathrm{C}$ were focused on identifying whether the random variable is discrete or continuous, identifying the relevant distribution, and identifying the parameters involved in the distribution. As Table 1 and Table 2 indicate, students in Class 2 performed better than the students in Class 1 when answering parts A, B and C in Quiz \#1. When answering these questions, one needs to read the given question well and understand it, and students in Class 2 demonstrated more comfort in this situation as they were trained to do this via the first step of Polya's problem-solving method.

Instructors who like to adapt a particular problem-solving method in their classes need to be patient at the beginning of the process. Most of the students do not have a habit of answering questions in a structured way. Even in Polya's problem-solving method, students tend to resist rewriting all the information they are given in the question, as is called for in the first step, understanding the problem. They try to argue, "Why do we need to repeat this information?" They do not understand how it becomes useful for them to find the answer at the end, until they work through several exercises. Therefore, the authors recommend discussing enough exercises using Polya's method until the students become habituated with it.

\section{Acknowledgments}

We thank the students and the human subject committee of the University for allowing us to conduct this study.

\section{References}

Alter, P. 2012. Helping students with emotional and behavioral disorders solve mathematics word problems. Preventing School Failure 56(1): 55-64. http://dx.doi.org/10.1080/1045988X.2011.565283 
Bayazit, I. 2013. An investigation of problem solving approaches, strategies, and models used by the $7^{\text {th }}$ and $8^{\text {th }}$ grade students when solving real-world problems. Educational Sciences: Theory \& Practice 13(3): 1920-1927.

Blanco, M., and M. Ginovart. 2009. Introducing the normal distribution by following a teaching approach inspired by history: An example for classroom implementation in engineering education. In Proceedings of the Sixth Conference of European Research in Mathematical Education, 2702-2711. Lyon, France.

Cobb, P., T. Wood, T., and E. Yackel. 1991. A constructivist approach to second grade mathematics. In Radical Constructivism in Mathematics Education, ed. E. von Glaserfield, 157-176. Dordrecht, The Netherlands: Kluwer Academic Publishers.

Devore, J. L. 2009. Probability and Statistics for Engineering and the Science. $7^{\text {th }}$ ed., Brroks/Cole, Cengage Learning.

Garfield, J. 1995. How students learn statistics. International Statistical Review 63(1): 25-34. http://dx.doi.org/10.2307/1403775

Gal, I., and J. B. Garfield. 1997. The assessment challenge in statistics education. IOS Press.

Gok, T. 2011. Development of Problem Solving Strategy Steps Scale: Study of validation and reliability. The Asia-Pacific Education Researcher 20(1): 15161.

Lin, G. 1995. Designing a web-based collaborative-learning module for statistical problem solving. British Journal of Educational Technology 42(3).

Marriott, J. 2009. Teaching, learning and assessing statistical problem solving. Journal of Statistics Education 17.

McClave, J. T., and T. Sincich. 2012. Statistics. 12th ed. Pearson / Prentice Hall Publishing Company.

Post, W. J., M. A. J. Duijn, and A. Boomsma. 2012. Teaching statistics: A tutorial on teaching hypothesis testing. Model Assisted Statistics and Applications 7:143-157.

Polya, G. 1973. How to solve it. Princeton, USA: Princeton University Press.

Richardson, M., and S. Haller. 2002. What is the probability of a kiss? Journal of Statistics Education. 10(3). http://www.amstat.org/publications/jse/v10n3/haller.html

Rumsey, D. J. 1998. A cooperative teaching approach to introductory statistics. Journal of Statistics Education 6(1).

Schifter, D., and C. Fosnot. 1993. Reconstructing mathematics education. NY: Teachers College Press.

Selvaratnam, M. 2011. Chemistry students' competence throughout their BSc course in some problem-solving strategies. South African Journal of Chemistry 64: 44-48. 
, and N. Mavuso. 2010. Competence of Science Foundation students in some simple strategies for problem solving. South African Journal of Science 106(5/6):184. http://dx.doi.org/10.4102/sajs.v106i5/6.184

Sotos, A. E. C., S. Vanhoof, W. V. Noortgate, and P. Onghena. 2007. Students' misconceptions of statistical inference: A review of the empirical evidence from research on statistics education. Educational Research Review 2: 98113. http://dx.doi.org/10.1016/j.edurev.2007.04.001

Xin, Y. P., D. Zhang, J. Y. Park, K. Tom, A. Whipple, and L. Si, L. 2011. A comparison of two mathematics problem-solving strategies: Facilitate algebra-readiness. The Journal of Educational Research 104(6): 381-395. http://dx.doi.org/10.1080/00220671.2010.487080

Yasin, R. M., L. Halim, and A. Ishar. 2012. Effects of problem-solving strategies in the teaching and learning of engineering drawing subject. Asian Social Science, 8(1): 16.

Yuan, S. 2013. Incorporating Pólya's problem solving method in remedial math. Journal of Humanistic Mathematics 3(1): 96-107. http://dx.doi.org/10.5642/jhummath.201301.08

Yunus, A. S. M., and W. Z. W. Ali. 2008. Metacognition and motivation in mathematical problem solving. The International Journal of Learning 15(3).

Zieffler, A., J. Garfield, S. Alt, D. Dupuis, K. Holleque, and B. Chang. 2008. What does research suggest about the teaching and learning of introductory statistics at the college level? A review of the literature. Journal of Statistics Education 16(2). 